\title{
SEISMIC STRUCTURAL ANALYSIS OF A CONCEPTUAL WASTE PACKAGE DESIGN FOR DISPOSAL OF HIGH LEVEL NUCLEAR WASTE IN A GEOLOGIC REPOSITORY
}

\author{
Zekai Ceylan \\ Scott M. Bennett \\ Thomas W. Doering
}

B\&W Fuel Company/Management and Operating Contractor

101 Convention Center Drive

Las Vegas, NV 89109

(702) 794-7934

(702) 794-7052
(702) $794-1857$

\section{ABSTRACT}

This paper describes the methodology used to perform seismic structural analyses on a conceptual waste package design for the disposal of high-level nuclear waste in a geologic repository. The waste package design analyzed is intended to hold uncanistered spent fuel. The purpose of this analysis is to determine if the proposed waste package design can withstand the seismic loads caused by nearby fault movement during the preclosure period of the repository without breaching the inner or outer waste package barriers or damaging the internal structures, which would affect their ability to separate the waste forms. For uncanistered spent fuel waste packages, this is interpreted to mean that no yielding of the basket structure is permitted.

The analysis was performed using the ANSYS finiteelement analysis code. The waste package is modeled as a three-dimensional solid. The seismic loads were applied as acceleration loads at supports. After the model was constructed, a modal solution was obtained to find the natural frequencies and mode shapes of the geometry. The results of the modal analysis were then used in a response-spectrum analysis. In the response-spectrum analysis, the seismic loads were applied to the model to determine stresses, strains and deflections. The input to the response spectrum is in the form of a table of acceleration versus frequency, thus making it a frequencydomain solution. A single-point response-spectrum is used, meaning that all supports of the model will experience the same ground movement. The ANSYS code allows only linear material properties in responsespectrum analyses, therefore, an elastic solution is obtained and allowable material stresses are based on the yield strength.

The results indicate that the waste package can withstand a seismic excitation of a $2 g$-load in magnitude between the frequencies of $0.001 \mathrm{~Hz}$ and $400 \mathrm{~Hz}$. It is also observed that there is an order of magnitude difference between the allowable and observed stress magnitudes on the waste package due to the seismic acceleration loading of this magnitude.

\section{INTRODUCTION}

The waste package performs a key role in substantially complete containment, waste isolation, criticality control, and waste retrievability. This paper describes the methodology used to perform seismic structural analysis on a conceptual waste package design. The purpose of this analysis is to determine if the proposed waste package design can withstand the seismic loads caused by nearby fault movement during the preclosure period of the repository without breaching the inner or outer waste package barriers or damaging the internal structures, which would affect their ability to separate the waste forms. For the uncanistered fuel waste packages, the ability to separate waste forms is interpreted to mean that no yielding of the basket structure is permitted.

The waste package seismic design considerations are closely related to the emplacement mode in the drift. Horizontal, in-drift emplacement is the current design assumption for waste package emplacement. Therefore, the finite-element model assumes that the waste package is supported at both ends by cradling it on a pedestal. 


\section{FINITE-ELEMENT MODELING}

A three-dimensional finite-element model of an uncanistered fuel (UCF) waste package (including inner and outer barriers, lids, structural angles, basket assembly, and spent nuclear fuel assembly weight) with the capacity to hold 21 pressurized water reactor (PWR) fuel assemblies is developed per current $\mathrm{M} \& \mathrm{O} / \mathrm{B} \& W$ Fuel Company/Waste Package Development designs.

The ANSYS 5.0A finite-element analysis code is used for the seismic structural analysis of the 21 PWR uncanistered fuel waste package. The model assumes the inner and outer barriers are fabricated as one piece. Properties, however, are unique to each barrier as they are two different metals. A SOLID45 3 -D solid-element type was chosen for this analysis. The SOLID45 element is defined by eight nodes, each having three degrees of freedom (translation in the nodal $x, y, z$ directions).

A modal solution is obtained by using a subspace iteration method to extract the mode shapes and natural frequencies of the waste package. Consequently, a linear single-point response spectrum analysis solution is produced, with base excitation as the only load on the system. Displacement constraints at support locations serve as the points of excitation in the vertical y-direction.

One of the assumptions in the finite-element model is that the material properties and displacement solution to the problem are linear because of the complex nature of modal and spectrum analyses. The ANSYS code allows only linear solutions to these type of analyses. Therefore, an elastic solution is obtained and allowable material stresses are based on the yield strength.

There is no damping specified in this finite-element analysis solution. Therefore, the results are considered conservative since the stress magnitudes will be larger due to the absence of damping in the waste package structure.

The frequency range of the response spectrum is selected from $0.001 \mathrm{~Hz}$ to $400 \mathrm{~Hz}$, which covers the first 14 mode shapes and corresponding natural frequencies. The reason for selecting this frequency range is to characterize the waste package response by including a sufficient number of modes in the solution phase. Using more modes provides a more accurate solution.

The response spectrum curve is defined by the frequency range versus spectral value, on the horizontal and vertical axes, respectively. The acceleration of the waste package in the y-direction is selected as the type of spectrum for the seismic analysis. Seismic loading with acceleration in the vertical direction, equal to gravitational acceleration " $g$ " (as recently observed during the Northridge Earthquake) ${ }^{3}$ could double the weight of the waste package. Therefore, a total load of $2 g$ is considered for the seismic acceleration input to the finite-element model.

The output from the finite-element solution consists of the participation factor table and the mode combination file. The participation factor is a combination of the normalized eigenvector, mass matrix, and a vector describing the excitation direction. The participation factor table lists the participation factors, mode coefficients, and the mass distribution for each mode. The mode coefficients are used to multiply the mode shapes to obtain the maximum response of each modet.

The final sequence of the solution process involves the combination of the maximum modal responses as specified by the mode combination file of ANSYS to calculate the overall response of the structure. The overall response consists of the overall displacements, stresses, strains, and reaction forces.

\section{RESULTS}

Figure 1 illustrates principal stress $\left(\mathrm{S}_{1}\right)$ distribution and a maximum tensile stress magnitude of $4.2 \mathrm{MPa}$. The maximum tensile stress is located at the support location. The maximum compressive stress ( $0.8 \mathrm{MPa})$, however, occurs on the outer barrier, close to the supports at both ends (see Figure 2).

Due to the cyclic nature of the problem, a fatigue analysis is also performed to determine if the waste package can withstand a specified cyclic load of maximum stress of $4.2 \mathrm{MPa}$. The frequency is assumed to be $400 \mathrm{~Hz}$, the maximum used in the analysis, and the duration of the earthquake is assumed to be 30 seconds. Thus, the waste package is assumed to go through 12,000 cycles.

\section{CONCLUSIONS}

The maximum-normal-stress theory is based on comparing the ultimate tensile and compressive strengths of the materials with the maximum values of tensile and compressive stresses they experience during an impact. The finite-element analysis of the 21 PWR uncanistered fuel waste package resulted in a maximum tensile stress value of $4.2 \mathrm{MPa}$. This value is below the yield-strength limits for all materials in the waste package (smallest yield-strength value is $172 \mathrm{MPa}$ ). The lowest value of ultimate compressive strength of the materials used in this 
model is also well above the maximum compressive stress magnitude $(0.8 \mathrm{MPa})$. Thus, it is determined, the waste package is able to withstand the seismic excitation of two times the gravitational acceleration without any permanent deformation on either the containment barriers or the basket assembly.

The allowable alternating stress for austenitic steels and nickel alloys at 12,000 cycles is $448 \mathrm{MPa}^{5}$. When the allowable cyclic load (448 MPa) is compared with the seismic simulation results (4.2 $\mathrm{MPa}$ ), it is observed that the waste package is far below the limiting stress magnitude according to the criteria set by the fatigue analysis. Therefore, the seismic loading will not cause any fatigue failure in the waste package.

\section{REFERENCES}

1. U. S. Department of Energy, Office of Civilian Radioactive Waste Management, "Seismic Design Methodology for a Geologic Repository at Yucca Mountain," Topical Report YMP/TR-003-NP, Las Vegas, Nevada, 1995.

2. Swanson Analysis Systems, Inc., "ANSYS User's Manual," Rev. 5.0, Vol. 3 Elements, DN-R300:50-3, December 23, 1992.

3. S. G. Ladkany and R. Rajagopalan, "Failure of MPC Overpack and Inner Container Under Corrosion and Mechanical Stresses In a Backfilled Drift," Sixth Annual High Level Radioactive Waste Management Conference, Las Vegas, Nevada, 1995.

4. Swanson Analysis Systems, Inc., "ANSYS User's Manual," Rev. 5.0, Vol. 1 Procedures, DN-R300:50-1, December 23, 1992.

5. ASME Boiler and Pressure Vessel Code, "Design Fatigue Curve for Austenitic Steels," Section III, Division 1, Appendix I, Fig.I-9.2.1, 1992 Edition.

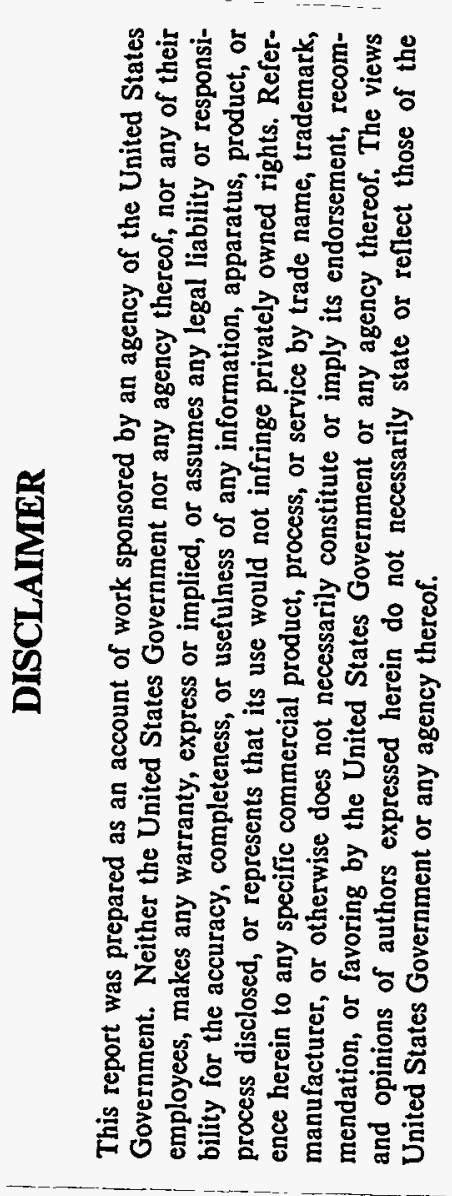




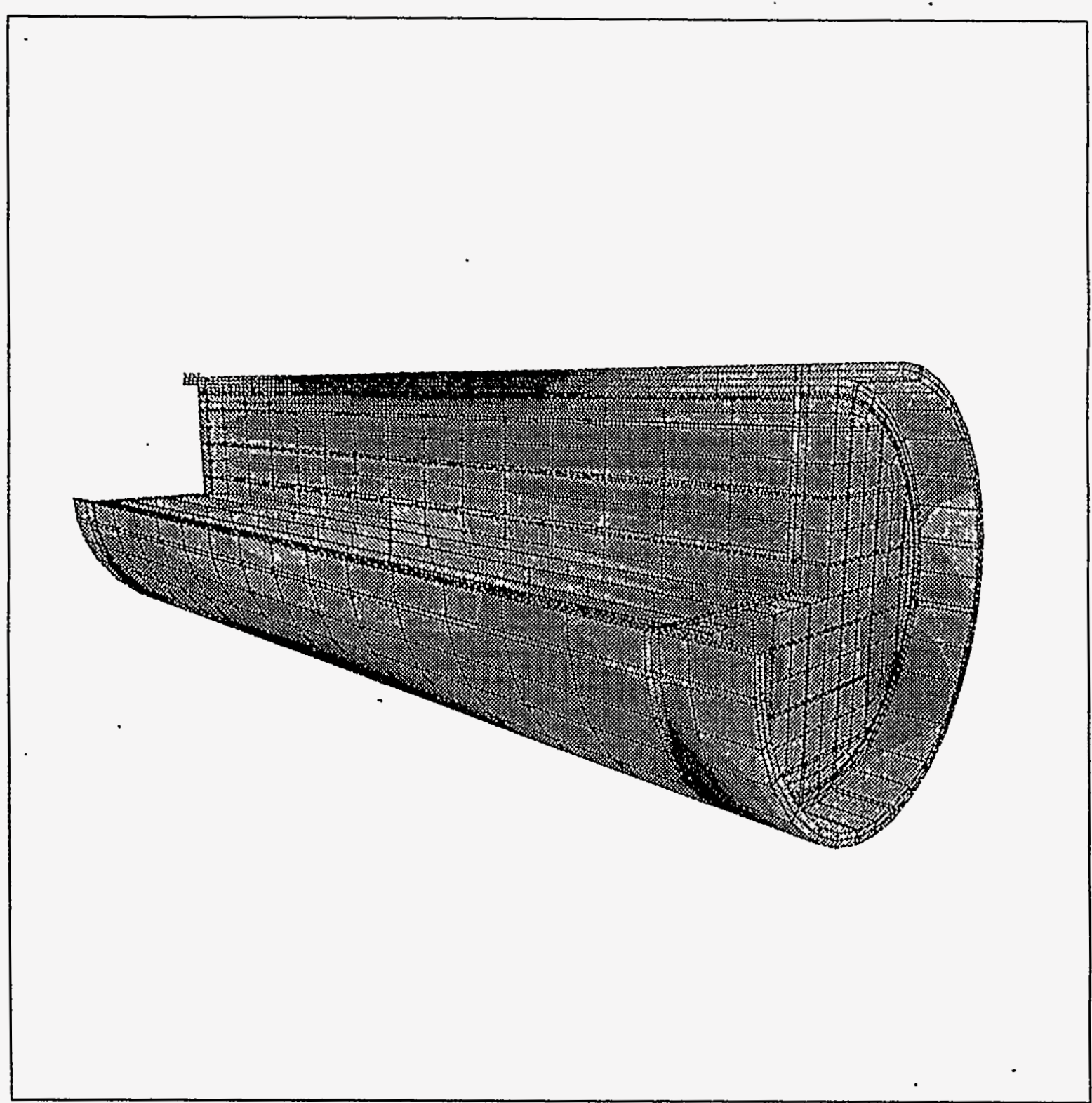

ANSYS $5.0 \mathrm{~A}$

SEP 181995

NODAL SOLUTION

S1

STRESS (Pa)

SMN $=102740$

$\operatorname{SMX}=.421 \mathrm{E}+07$

102740

110000

300000

800000

$.125 \mathrm{E}+07$

$.140 \mathrm{E}+07$

$160 \mathrm{E}+07$
$.300 \mathrm{E}+07$
.42107

$.421 \mathrm{E}+07$

Figure 1. 21 PWR Uncanistered Fuel Waste Package First Principal Stress Contour 


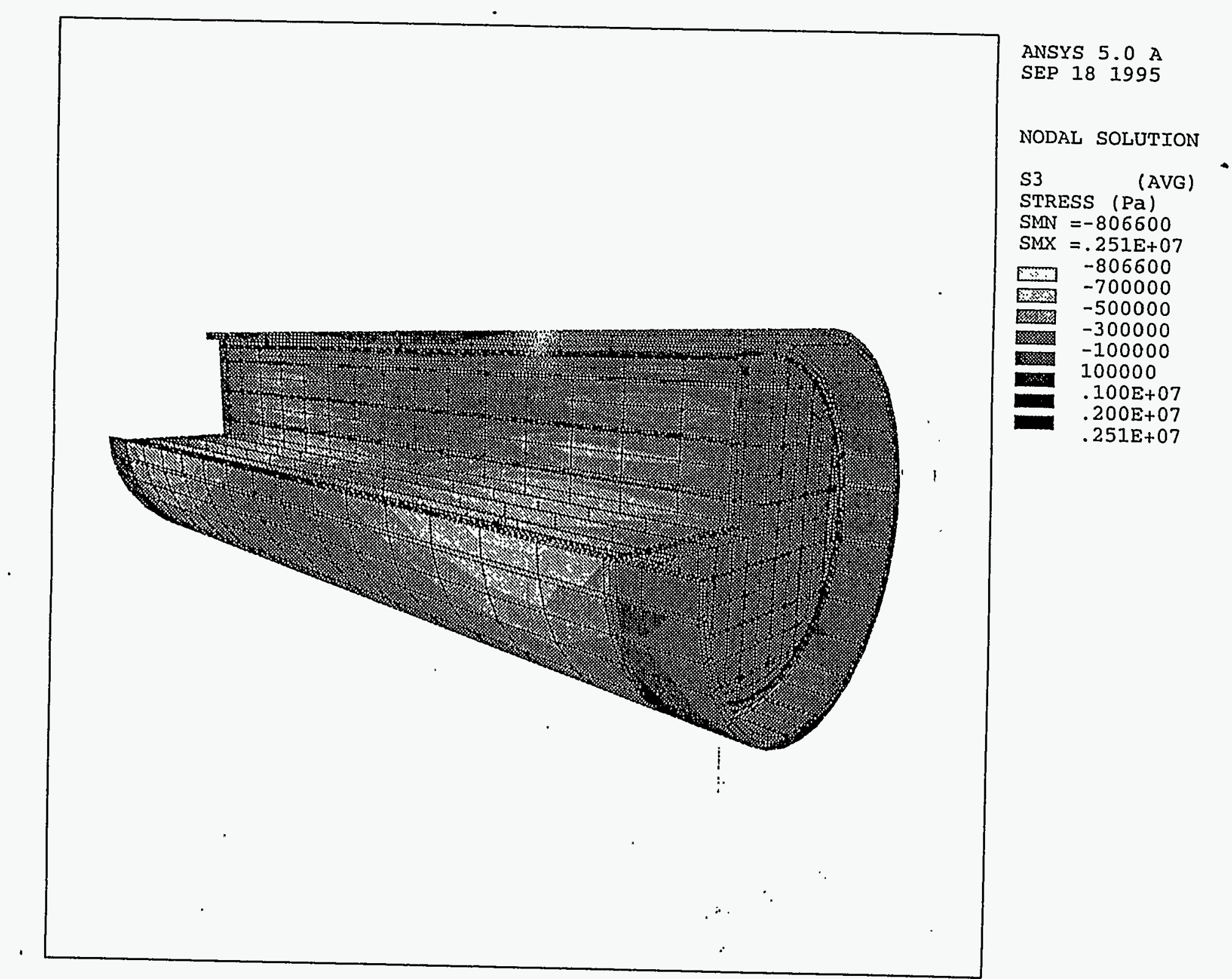

Figure 2. 21 PWR Uncanistered Fuel Waste Package Third Principal Stress Contour 